\title{
Effect of Lubricant Content and Forming Temperature to the Green Characteristics of Fecral Powder Compacts Formed at Elevated Temperature
}

\author{
M.M. Rahman, M.A. Ismail and V. Karthiyani \\ Department of Mechanical Engineering, Universiti Tenaga Nasional (UNITEN) \\ Putrajaya Campus, Jalan Ikram 43000 Kajang, Selangor, Malaysia, \\ mujibur@uniten.edu.my; Tel.: +603-89297269; Fax: +603-89212116
}

\begin{abstract}
This study presents an experimental investigation on the effect of lubricant content and forming temperature to the properties of green products of FeCrAl powder mass formed through warm powder compaction route. Iron powder ASC 100.29, chromium and aluminum powder were used as a base powder along with different weight percentage of zinc stearate $(0-0.4 \mathrm{wt} . \%)$ as lubricant to produce green products. The base powder and lubricant were mixed mechanically in a low speed powder mixer $(30 \mathrm{rpm})$ at room temperature to prepare the feedstock. The powder mass was subsequently compacted at 100,150 and $200^{\circ} \mathrm{C}$ by applying 425 MPa of axial loading simultaneously from upward and downward directions. The as-pressed samples or better known as green compacts were characterized for their physical and mechanical properties and their microstructures were evaluated through Scanning Electron Microscopy (SEM). The result revealed that the application of lubricant is vital in order to ease the ejection process and to produce defect-free green compacts with good surface finish. The results also showed that the forming temperature of $100-150^{\circ} \mathrm{C}$ and a lubricant content of $0.3 \mathrm{wt} . \%$ significantly influenced the properties and microstructures of green compacts.
\end{abstract}

Key words: $\mathrm{FeCrAl}$ powder mass, green compacts, mechanical properties, microstructures, influenced, application

\section{INTRODUCTION}

A coherent mixture of $\mathrm{FeCrAl}$ or Fecralloy is a high temperature alloy used as engineering materials due to its high strength, improved form stability at high temperature, corrosion oxidation/resistance and longer high temperature life. This alloy is formed through foundry or mechanical alloying process. Foundry process requires huge amount of heat to melt all the metals whereas mechanical alloying method requires the elements in powder form to be mixed by a high energy ball mill for a long time. Both methods require further, processing to produce end products which are time and energy consuming hence expensive. Another option to produce $\mathrm{FeCrAl}$ alloy is through powder metallurgy, which is an effective innovation given its high exactness and near-net-shape or net-shape production capability. Powder metallurgy is an essential term used to portray the handling, assembling and properties of metallic powder and may incorporate non-metallic powders that are utilized to convert into discrete and usable shapes. Notwithstanding the process has been presented more than 100 years, over the past quarter century, it has ended up being extensively seen as an exceptional strategy for conveying exclusive requirement quality parts for the generation of different applications (Chandramouli et al., 2007). This achievement is an immediate after effect of the focal concentrations to the drawbacks of other metal shaping technologies, i.e., amassing and metal casting and different shape appearance. Thus, making powder metallurgy an obvious better advancement. One of the advancement in powder metallurgy is powder compaction which can be conducted either at room temperature, i.e., cold compaction or at elevated temperature, i.e., warm compaction (Rahman and Nor, 2009; Zhao et al., 2011).

Lubricant plays an important role in powder compaction process as it is used to reduce the adhesion and frictional force generated among the powder particles and between the powder mass and die wall due to the relative movement between punches and the die wall. The addition of lubricant is also to ease the ejection of the shaped part from the solid die and reduces the wearing of the tools. However, it has an adverse effect on density

Corresponding Author: M.M. Rahman, Department of Mechanical Engineering, Universiti Tenaga Nasional (UNITEN) Putrajaya Campus, Jalan Ikram, 43000 Kajang, Selangor, Malaysia mujibur@uniten.edu.my; Tel. +603-89297269; Fax: +603-89212116 
and powder flow characteristics, since, lubricant is a polymer with very low density and melting point (Rahman et al., 2011a, b). There are two methods of lubrication, i.e., die wall lubrication and admixed lubrication. It has been proven that admixed lubrication is more effective than die wall as it guarantees a more noteworthy compression of powder. The friction generated hinders the transmission of pressure and the density gradient inside the green products (Rahman et al., 2013). Therefore, the utilization of lubricant is necessary to diminish the variation of density by advancing more homogenous pressure transmission.

Forming temperature is found to have the significant effect to the green properties of powder compacts formed at elevated temperature (Rahman and Yogaswerarow, 2016), since, warm compaction is effective to be conducted at a temperature below the recrystallization temperature of the main powder constituent. The admixed lubrication in a full cycle of powder compaction process has been studied extensively (Nor et al., 2008) by using iron powder ASC 100.29 as main powder constituent, mixture of zinc stearate and activated carbon powder were used as lubricant. The researcher reported that a lubricant content of $0.5 \mathrm{wt} . \%$ and forming temperature of $130^{\circ} \mathrm{C}$ is suitable in producing high density yet defect free products. Another study compared the forming of iron powder with and without lubricant (Rahman et al., $2011 \mathrm{a}, \mathrm{b})$ where iron powder was mechanically mixed with 0.4 wt. $\%$ and $0.8 \%$ of zinc stearate. The powder mass was formed at $30-200^{\circ} \mathrm{C}$. The results revealed that a lubricant content of 0.8 wt. $\%$ and forming temperature of $180^{\circ} \mathrm{C}$ could produce defect-free yet high strength green compacts. However, to the best of the researchers knowledge, the studies related to the effect of forming tempereature and lubricant content to the green properties of $\mathrm{FeCrAl}$ powder compacts is not available anywhere. Therefore, the aim of this study is to fill this research gap.

\section{MATERIALS AND METHODS}

The experiments consist of three consecutive steps, i.e., powder mass preparation, shaping of powder mass and green product characterization. Iron powder ASC 100.29 having particle size range of $20-180 \mu \mathrm{m}$ was used as main powder constituent, since, this type of powder has been in use in most of the powder compaction industries. Two other elemental powders, i.e., Chromium (Cr) and Aluminum (Al) were used as alloying element whereas zinc stearate was used as admixed lubricant. The composition of chromium was 10 (wt.\%) the aluminum was 5 (wt.\%), zinc stearate was varied, i.e., $0,0.2$ and 0.4 (wt.\%) and the rest was iron powder. All of these elemental powders and lubricant were mixed mechanically through a low speed $(30 \mathrm{rpm})$ powder mixer for $30 \mathrm{~min}$ at room temperature. A lab-scale uniaxial die compaction rig was designed and fabricated to shape metal powder mass at above ambient temperature. The cylindrical shape die cavity of $20 \mathrm{~mm}$ diameter was filled with the as-prepared powder mass. The top punch was brought closer to the upper level of the powder mass. The die assembly together with the powder mass was heated to 100,150 , and $200^{\circ} \mathrm{C}$ and kept for $30 \mathrm{~min}$ for the uniform heating of the die assembly and the filled powder mass.

The powder mass was subsequently compacted by applying simultaneous downward and upward loading of $425 \mathrm{MPa}$. Once the desired loading is achieved, the top punch was kept at that position for a while for the settlement of the powder particles and brought back to the initial position which enabled the spring-back or release of residual stress from the powder compact. The as-pressed powder compact termed as green compact was subsequently ejected from the die cavity by means of bottom punch. All the green samples were inspected visually for any defects or cracks and surface finish.

Dimensions of the green samples were measured to analyze the shape distortion from where the green density was calculated. The dimensional measurement was conducted through a digital Vernier Calliper (Model: CD-6"CS, S/N: 04171546) with an accuracy of $+/-0.01$ in). The flexure stress was measured through three point bending test machine (Brand: Instron, Model: Instron 3365, S/N:SAA61569) following the standard (ASTM E290-09). Each sample was hold tightly at both ends, force was applied at the middle of the sample until it was broken down (Fig. 1). The image of the fractured surface of each

(a)

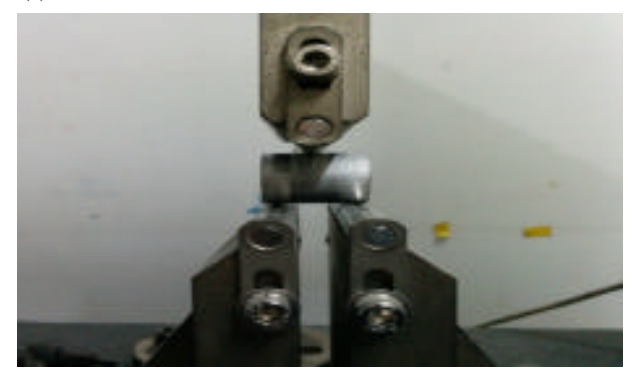

(b)

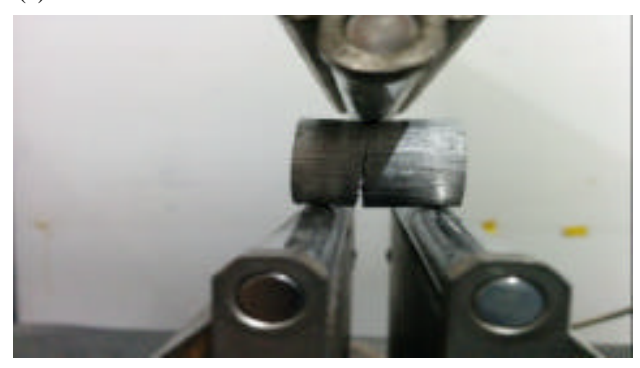

Fig. 1: Three-point bending test: a) As mounted green sample and b) After application of load 
sample was captured through scanning electron microscopy (Brand: JEOL, Model: JSM 601 OPLUS/LA).

\section{RESULTS AND DISCUSSION}

The density of the green compacts with different lubricant content, formed at different temperature is depicted in Fig. 2 from where it is evident that the density of green compacts is higher for all the weight percentage of lubricant at a forming temperature of $100^{\circ} \mathrm{C}$ compared to the density of green compacts at a forming temperature of 150 and $200^{\circ} \mathrm{C}$. The density of green compacts is lowest when there is no lubricant added into it.

The density is at the peak when the weight percentage of lubricant is $0.3 \%$ which shows that 0.3 wt. $\%$ of lubricant acts as dominant to achieve the optimum density. The lubricant content beyond $0.3 \mathrm{wt} . \%$ results in lower density because the lubricant might hinder pore closures amid compaction. Meanwhile the density of the samples with lubricant increases when the powder is compacted at $100^{\circ} \mathrm{C}$ then there is a sharp decrease at $150^{\circ} \mathrm{C}$ and levels off after at a decreasing amount at $200^{\circ} \mathrm{C}$. This is because the melting point of zinc stearate is approximately $120^{\circ} \mathrm{C}$, therefore, at high temperature in this case $200^{\circ} \mathrm{C}$, contributes to a high tendency of the lubricant spillage towards the die surface during the compaction process.

The surface finish of the green compacts was also found to be dependent on the forming temperature. The green compact formed without lubricant at low temperature has nicer surface finish and much easier to be removed during the ejection process compared to the green compact formed at high temperature. The process of ejection was harder without lubricant at the temperature of 150 and $200^{\circ} \mathrm{C}$ because it made the compact to get stuck in the die. This led to incomplete compaction that caused burn defects at the surface of the green compact. The inter-particle friction that occurs

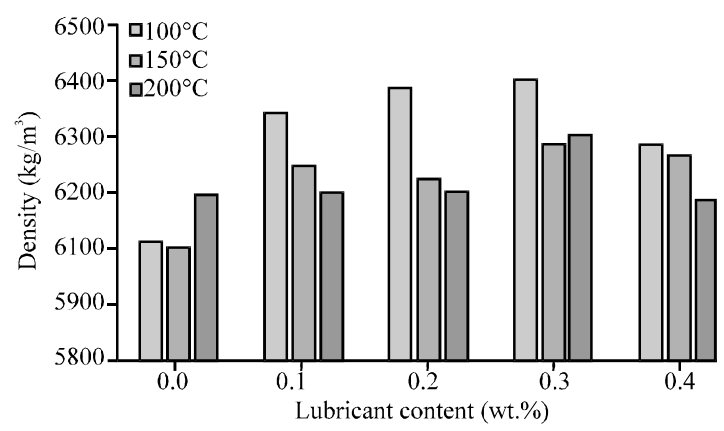

Fig. 2: Density of green cmpacts with different lubricants content within the powder particles and die-wall during compaction contributes to inhomogeneous density distribution that prompts to crack in the internal part of the green compact during ejection process.

Flexure stress is found to be peak at a forming temperature of $200^{\circ} \mathrm{C}$ without lubricant (Fig. 3). An increasing trend in the value of flexure stress can be observed when the compaction temperature increases from $100-200^{\circ} \mathrm{C}$ with 0 and 0.2 wt. $\%$ of lubricant whereas the flexure stress decreases significantly for $0.4 \mathrm{wt} \%$ of lubricant as temperature increases. This clearly shows that flexure stress is the lowest at higher compaction temperatures at high amount of lubricant. Figure 4-7 depict the SEM images of fractured surfaces of nine green samples with different lubricant content, $0,0.2$ and 0.4 wt.\% formed at different temperature, i.e., 100, 150 and $200^{\circ} \mathrm{C}$. It is clear in Fig. 4 that particles of the green compact did not assimilate appropriately within each other at the green compact formed without lubricant, therefore, leaving more interconnected pores in the
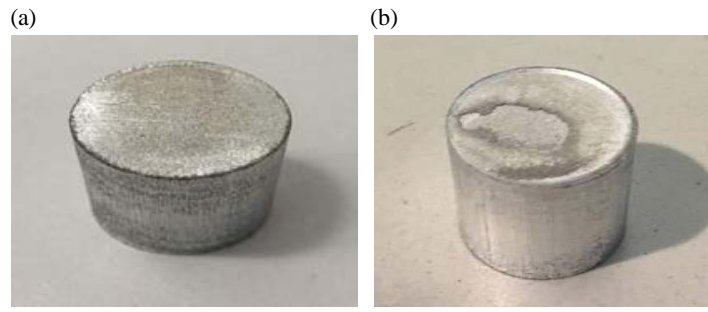

(c)

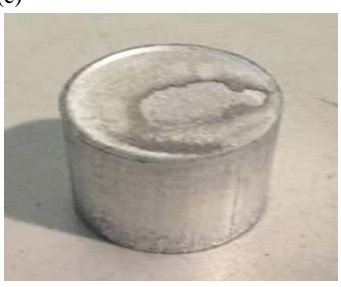

Fig. 3: Green compacts formed at different temperature without lubricant: a) $100^{\circ} \mathrm{C}$; b) $150^{\circ} \mathrm{C}$ and c) $200^{\circ} \mathrm{C}$

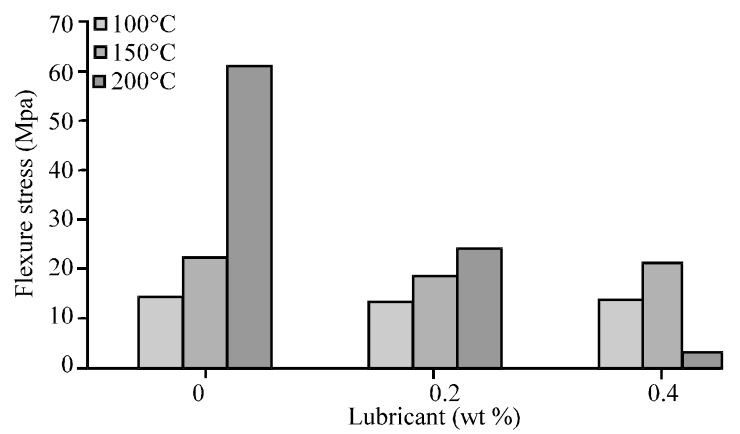

Fig. 4: Flexure stress of green compacts with different lubricant content 
(a)

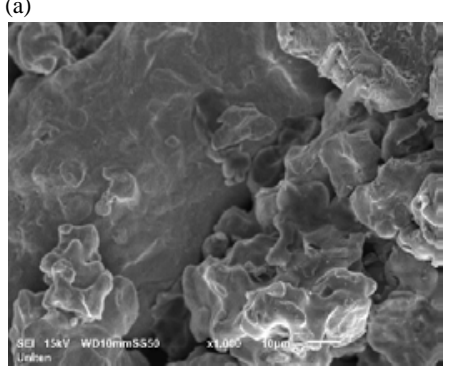

(b)

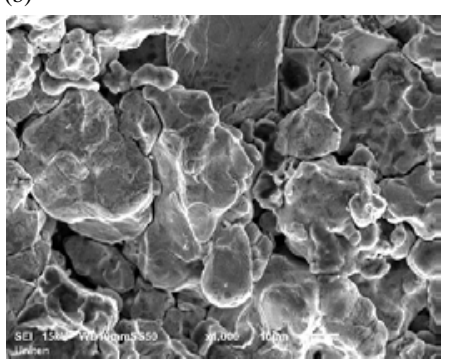

(c)

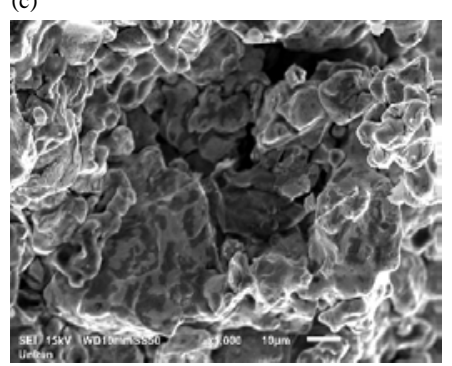

Fig. 5: Green compacts formed at $100^{\circ} \mathrm{C}$ with different lubricant content: a) 0 ; b) 0.2 and c) 0.4 wt.\%

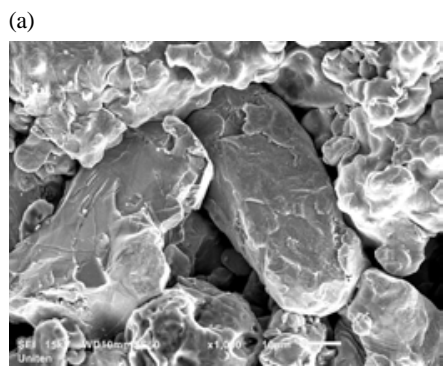

(b)

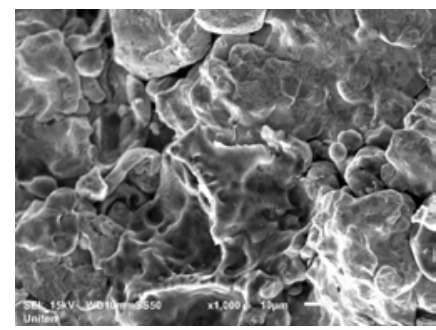

(c)

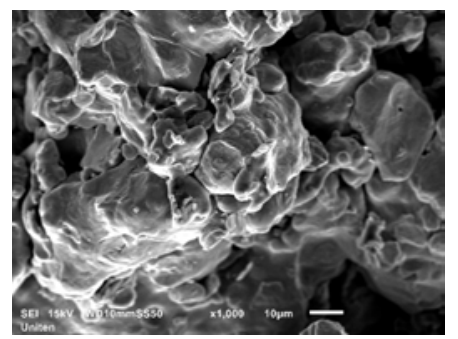

Fig. 6: Green compacts formed at $150^{\circ} \mathrm{C}$ with different lubricant content: a) 0 ; b) 0.2 and c) 0.4 wt.\%

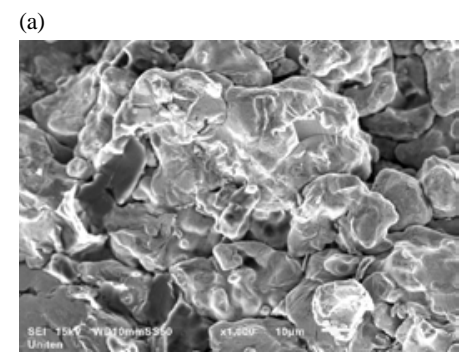

(b

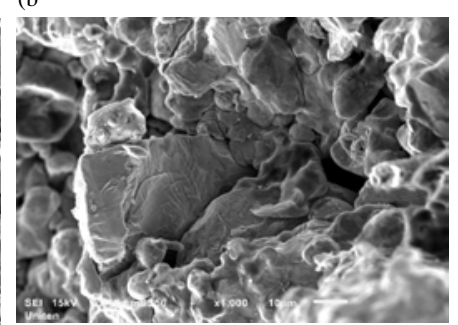

(c)

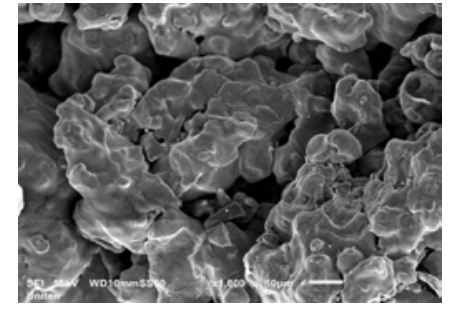

Fig. 7: Green compacts formed at $200^{\circ} \mathrm{C}$ with different lubricant content: a) 0 ; b) 0.2 and c) 0.4 wt.\%

compact. The arrangement and fusion of particles are irregular, hence leaving bigger boundaries among the particles. At a forming temperature of $100^{\circ} \mathrm{C}$, the inter-particle bonding among the powder particles are weak which exhibits less densification (Fig. 1) results in low quality green compacts for further handling.

Figure 5, generally the powder particles are more densified compared to the green compacts formed at $100^{\circ} \mathrm{C}$. It shows reduction of interconnected pores and boundaries among the powder particles with a larger grain size filling up each other. Powder mass mixed with 0.2 and 0.4 wt. \% of zinc stearate Fig. $5 \mathrm{~b}$ and c was found to have good assimilation and arrangement of powder particles compared to $0 \mathrm{wt} \%$ of zinc stearate (Fig. 5a). This might be due to the increase in zinc stearate tends to fill up the pores among powder particles. Furthermore, at high temperatures, the grain size of the powder particles tends to expand due to thermal expansion which thereby relates to the increase in density. It is clear in Fig. 6 that the assimilation and inter-particle bonding of the powder particles are well distributed and almost perfect when the powder mass is formed at $200^{\circ} \mathrm{C}$. There are less interconnected pores within the powder particles for samples without lubricant 0 wt.\%, (Fig. 6a) and 0.2 wt.\% of lubricant (Fig. 6b) compared to sample mixed with $0.4 \mathrm{wt} . \%$ of lubricant. The forming temperature was found to have a significant effect on the microstructure of the green compacts due to the influence of thermal expansion which contributed to the expansion of grain size.

\section{CONCLUSION}

Green properties and microstructures of $\mathrm{FeCrAl}$ powder compacts mixed with different zinc stearate (as lubricant) content, formed at different temperature are evaluated. The results revealed that zinc stearate and forming temperature affect the quality of green compacts. 
A lubricant content of $0.3 \mathrm{wt} \%$ and a forming temperature of $150^{\circ} \mathrm{C}$ are found to be suitable to produce high density and stronger green compacts having more uniform microstructure. In order to evaluate the efficacy of the lubricant content and forming temperature, the green compacts are required to be sintered and subsequently evaluate the final properties.

\section{ACKNOWLEDGEMENT}

This research is financially supported by Universiti Tenaga Nasional through the BOLD research grant 10289176/B/9/2017/35.

\section{REFERENCES}

Chandramouli, R., T.K. Kandavel, D. Shanmugasundaram and T.A. Kumar, 2007. Deformation, densification and corrosion studies of sintered powder metallurgy plain carbon steel preforms. Mater. Des., 28: 2260-2264.

Nor, S.S.M. , M.M. Rahman, F. Tarlochan, B. Shahida and A.K. Ariffin, 2008. The effect of lubrication in reducing net friction in warm powder compaction process. J. Mater. Process. Technol., 207: 118-124.
Rahman, M.M. and S.R. Yogaswerarow, 2016. Effects of compaction and sintering temperature to the alloyability of $\mathrm{FeCrCu}$ powder mixture. Adv. Mater. Res., 1133: 264-268.

Rahman, M.M. and S.S.M. Nor, 2009. An experimental investigation of metal powder compaction at elevated temperature. Mech. Mater., 41: 553-560.

Rahman, M.M., S.S.M. Nor and A.K. Ariffin, 2013. Effect of lubricant content to the properties of Fe-based components formed at above ambient temperature. Proc. Eng., 68: 425-430.

Rahman, M.M., S.S.M. Nor, A.T. Rahman and H.Y. Rahman, 2011a. The effects of lubrication in near-net shape manufacturing process through warm forming route. ASM. Sci. J., 5: 11-18.

Rahman, M.M., S.S.M. Nor, H.Y. Rahman and T.J. Saktisahdan, 2011b. Warm forming of iron powder with and without admixed lubricant. Solid State Sci. Technol., 19: 301-311.

Zhao, C., M.K. Jain, M. Bruhis and R. Lawcock, 2011. An integrated study of die powder fill, transfer and compaction process using digital image correlation method. Powder Technol., 208: 225-230. 